\title{
Impact of COVID-19 Pandemic during the Lockdown on the Traumatic Brain Injury-An Institutional Experience
}

\author{
Nitish Nayak ${ }^{1}$ Prashant Raj Singh ${ }^{1}$ Raghvendra Kumar Sharma ${ }^{1}$ Surendra Kumar Gupta ${ }^{1}$ \\ Charandeep Singh Gandhoke ${ }^{1}$ Anil Kumar Sharma ${ }^{1, \odot}$ \\ ${ }^{1}$ Department of Neurosurgery, All India Institute of Medical \\ Sciences - Raipur, Chhattisgarh, India

\begin{abstract}
Address for correspondence Anil Kumar Sharma, MCh, Department of Neurosurgery, All India Institute of Medical Sciences - Raipur, Raipur 492099, Chhattisgarh, India
\end{abstract} \\ (e-mail: dr.anilsharma02@gmail.com).
}

Indian J Neurotrauma 2022;19:7-11.

\begin{abstract}
Keywords

- traumatic brain injury

- COVID

- pandemic

- lockdown

- road traffic accident

Background Traumatic brain injuries (TBIs) contribute to a significant socioeconomic impact, primarily affecting the lower-income sections of the society. The COVID-19 pandemic has resulted in a marked reduction in in-patient attendance. We are highlighting the impact of lockdown in neurotrauma cases in our institution compared to the prelockdown period.

Methods We have done the retrospective review of the patients admitted due to TBI in prelockdown (January 14-March 21, 2020) and lockdown period (March 25-May 31, 2020) for the same duration of the 68 days at our tertiary institution. We have included demographic characteristics (age, sex), mode of injury, the severity of TBI, radiological diagnosis (computed tomography scan), and treatment obtained in our study. We compared the data for percentage (\%) reduction of TBI cases and factors responsible for it during the lockdown period.

Result A total of 166 patients were included in both groups. TBl's most common mechanism was road traffic accident, but we observed an increase in self-fall (16.9\% vs. $38.1 \%)$ and assault (11.2\% vs. $19 \%$ ) during the lockdown period. We have noted that moderate TBI increased during the lockdown period by $17 \%$. Overall, there is a reduction of $67 \%$ in TBI cases during the lockdown period.

Conclusion The COVID pandemic has limited road traffic activity, and strict implementation of lockdown has restricted the infection and has reduced the neurotrauma emergencies. Simultaneously, moderate TBI cases have increased because of the lack of transportation facility and delay in the management of mild TBI cases.
\end{abstract}

\section{Introduction}

Traumatic brain injuries (TBIs) are at the forefront, resulting in many hospitalization, disability, death, and socioeconomic losses. TBIs in India are increasing over a period of time, have more number of younger individuals due to high-velocity trauma, and contribute to a significant socioeconomic impact, primarily affecting the lower income sections of the society. ${ }^{1,2}$

In India, there was reporting of the first case of coronavirus infection (COVID-19) from Thrissur, Kerala, on January 30, 2020; and in the Chhattisgarh State of India, the first case of published online April 15, 2021
DOI https://doi.org/ $10.1055 / \mathrm{s}-0041-1725569$ ISSN 0973-0508. (c) 2021. Neurotrauma Society of India.

This is an open access article published by Thieme under the terms of the Creative Commons Attribution-NonDerivative-NonCommercial-License, permitting copying and reproduction so long as the original work is given appropriate credit. Contents may not be used for commercial purposes, or adapted, remixed, transformed or built upon. (https://creativecommons.org/licenses/by-nc-nd/4.0/).

Thieme Medical and Scientific Publishers Pvt. Ltd. A-12, 2nd Floor, Sector 2, Noida-201301 UP, India 
COVID-19 was detected on March 19, 2020, in Raipur. ${ }^{3}$ Since then, COVID cases have been rising rapidly, and now India has become the most affected nation in the world after the United States. The lockdown to prevent community spread in India was implemented from March 25 to May 31, 2020.4 There was a marked reduction in the in-patient attendance and neurotrauma cases during this lockdown period..$^{5-7}$ We highlight the impact of lockdown in neurotrauma cases in our institution and compare them with the prelockdown period of the same duration.

\section{Material and Method}

We have collected the data retrospectively during the COVID 19 prelockdown and lockdown period at our tertiary institution. We have dichotomized the prelockdown (January 14March 21) and lockdown group (March 25-May 31) for the same duration of the 68 days. During the study period, we have admitted a total of 166 patients of TBI in neurotrauma. We have included demographic characteristics (age, sex), mode of injury, the severity of TBI, radiological diagnosis (computed tomography scan), and treatment obtained in our study. We have categorized the TBI into mild, moderate, and severe, according to the Glasgow Coma Scale. The patients admitted for other neurosurgical conditions such as spontaneous intracerebral hemorrhage, stroke, aneurysmal subarachnoid hemorrhage, and spinal injury were excluded from the study.

During the COVID period, we changed our admission policy in neurotrauma and divided our trauma ward into two divisions. First, we admit a patient in a trauma screening block; then, the COVID-19 sample is sent immediately. If we get a negative report, we shift the patient to our neurotrauma block; and in case of a positive report, we shift the patient to the COVID ward. In case of urgent surgical intervention, we immediately transfer the patient to operation theater and operate with all the preventive measures. After the surgery, we shift the patient to the trauma screening block and then decide further the patient's transfer as per the COVID report.

\section{Statistical Analysis}

Descriptive and comparative data analyses were done using Statistical Package for Social Sciences (SPSS version 26:0). Qualitative data variables were expressed by using frequency and percentages (\%).

\section{Results}

During the study period, 166 patients were admitted due to TBI in the neurotrauma unit. There was a gradual decline in cases of TBI during our study period and showed 48 patients on January, 39 in February, 37 in March (before 22nd), 4 on March 25 to March 31, 13 in April, and 25 in May (-Fig. 1). - Table 1 summarizes the comparative findings between the prelockdown and lockdown period.

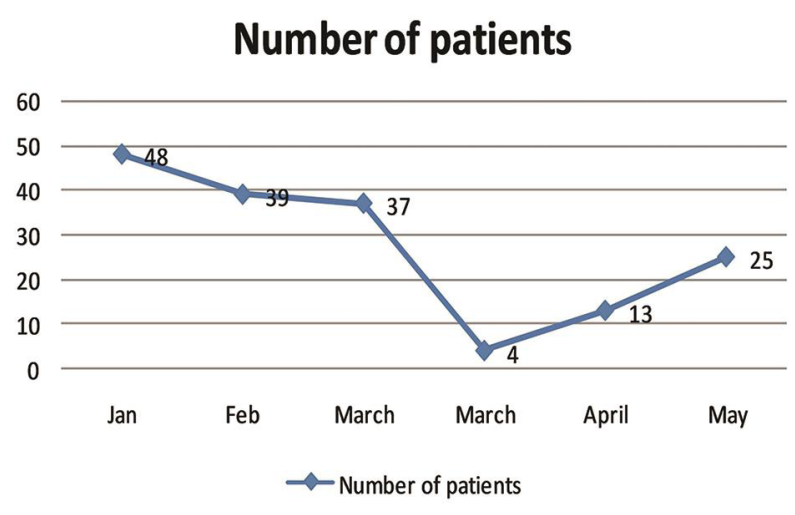

Fig. 1 Line diagram shows monthly frequency distribution of admitted traumatic brain injury (TBI) cases.

\section{Prelockdown Period}

A total of 124 patients were admitted in the prelockdown period. On demographic analysis, the average age of admitted patients was 36.41 years (range 15-70 years). Out of them, 73.4\% (91/124) were male, and 26.6\% (33/124) were female. The most common mode of injury was road traffic accident (RTA) seen in 71.8\% (89/124) patients; other modes of injury were self-fall $16.9 \%(21 / 124)$ and assault $11.2 \%$ (14/124). Most of the TBI patients had mild head injury $69.4 \%$ (86/124), while moderate TBI in 19.4\% (24/124) and severe head injury in $11.2 \%(14 / 124)$. The most common radiological diagnosis was a contusion, seen in 54.03\% (67/124). In comparison, we found acute subdural hematoma (aSDH) in $22.6 \%$ $(28 / 124)$, depressed fracture in $12.1 \%(15 / 124)$, extradural hematoma (EDH) in $6.4 \%(8 / 124)$, and diffuse axonal injury (DAI) in 4.8\% (6/124). Surgical intervention was performed in $14.5 \%$ (18/124) patients, and out of these 3 patients died. A total of 5 patients died during this period (4.03\%). On average, $1.82(124 / 68)$ patients/day got admitted in the neurotrauma unite during the prelockdown period.

\section{Lockdown Period}

A total of 42 patients were admitted during the lockdown period. On demographic analysis, the average age of admitted patients was 40 years (range 18-75 years) with a gender distribution of male $76.2 \%$ (32/42) and female $23.8 \%$ (10/42). In the mode of injury, RTA was seen in $42.9 \%$ (18/42) patients, self-fall in 38.1\% (16/42), and assault in 19\% (8/42). Mild TBI was seen in 61.9\% (26/42), moderate TBI in 33.3\% (14/42), and severe TBI was found in 4.7\% (2/21). In imaging, contusion was seen in $45.3 \%$ (19/42), aSDH in $21.4 \%$ (9/42), depressed fracture in $14.3 \%$ (6/42), EDH in 12\% (5/42), and DAI was found in $7 \%$ (3/42). Surgical intervention was done in $9.5 \%$ (4/42) cases and out of which 1 died. A total of 2 patients died during this period (4.8\%). On average, 0.62 patients/day (42/68) got admitted to the neurotrauma unit during the lockdown period. 
Table 1 Comparative findings between the prelockdown and lockdown period

\begin{tabular}{|c|c|c|c|c|}
\hline & $\begin{array}{l}\text { Prelockdown } \\
\text { (January 14-March 21) }\end{array}$ & $\begin{array}{l}\text { Percentage (\%) } \\
\text { distribution }\end{array}$ & $\begin{array}{l}\text { Lockdown } \\
\text { (March 25-May 31) }\end{array}$ & $\begin{array}{l}\text { Percentage (\%) } \\
\text { distribution }\end{array}$ \\
\hline Total & 124 & & 42 & \\
\hline Male & 91 & 73.4 & 32 & 76.2 \\
\hline Female & 33 & 26.6 & 10 & 23.8 \\
\hline Average age & 36.41 & & 40 & \\
\hline \multicolumn{5}{|l|}{ Severity of TBI } \\
\hline Mild & 86 & 69.4 & 26 & 62 \\
\hline Moderate & 24 & 19.4 & 14 & 33.3 \\
\hline Severe & 14 & 11.2 & 2 & 4.7 \\
\hline \multicolumn{5}{|l|}{ Mechanism of trauma } \\
\hline RTA & 89 & 71.8 & 18 & 42.9 \\
\hline Self-fall & 21 & 16.9 & 16 & 38.1 \\
\hline Assault & 14 & 11.2 & 8 & 19 \\
\hline \multicolumn{5}{|l|}{ Radiological diagnosis } \\
\hline Contusion & 67 & 54.03 & 19 & 45.3 \\
\hline $\begin{array}{l}\text { Acute subdural } \\
\text { hematoma }\end{array}$ & 28 & 22.6 & 9 & 21.4 \\
\hline Depressed fracture & 15 & 12.1 & 6 & 14.3 \\
\hline $\begin{array}{l}\text { Extradural } \\
\text { hematoma }\end{array}$ & 8 & 6.4 & 5 & 12 \\
\hline $\begin{array}{l}\text { Diffuse axonal } \\
\text { injury }\end{array}$ & 6 & 4.8 & 3 & 7 \\
\hline \multicolumn{5}{|l|}{ Intervention } \\
\hline Medical & 106 & 85.5 & 38 & 90.5 \\
\hline Surgical & 18 & 14.5 & 4 & 9.5 \\
\hline Mortality & 5 & 4.03 & 2 & 4.8 \\
\hline
\end{tabular}

Abbreviations: RTA, road traffic accidents; TBI, traumatic brain injury.

\section{Discussion}

According to the Global Burden of Disease (GBD) Study-2016, over a quarter of the world's trauma deaths occur in India. ${ }^{8}$ According to the World Health Organization Global Status Report on Road Safety, 2018, RTAs are the 8th leading cause of death in all age groups. ${ }^{9}$ The GBD Study-2016 has also evaluated and found three leading causes of injury of TBI in India that increased from 1990 to 2016 (road injuries 65.1\% [53.4-76.6], falls $41.3 \%$ [17.4-59.5], and self-harm $29.8 \%$ [15.2-52.4]). ${ }^{8}$ A systemic review of quantitative research in TBI has shown that RTA (55.5\%) and falls (29.2\%) were the most commonly reported mechanism of injury for TBI in India. ${ }^{1}$ Similarly, in our study, RTA is the most common mode of injury in both cohorts with a higher frequency in the prelockdown period (71.8\% vs. 42.9\%) (-Fig. 2). Ministry of Road Transport, the Government of India, in 2018 has released the statistics that Chhattisgarh state has a total of 13,864 road accidents (11th in all the states) and 4,592 persons killed (15th in all the states) in RTA. ${ }^{10}$ They also discussed the road network and showed that highways (National and State) accounted for $55.4 \%$ of the RTA in 2018. During this

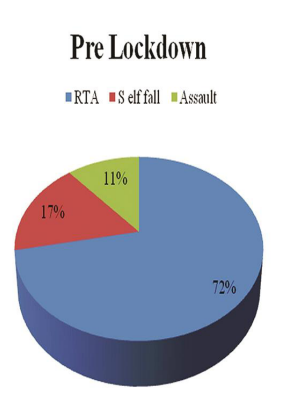

\section{Lockdown}

$\backsim$ RTA $\backsim$ Selffall $\|$ Assault

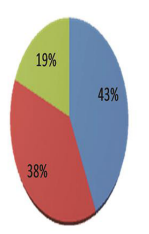

Fig. 2 Pie chart shows difference of distribution of mode of injury during the prelockdown and lockdown period.

lockdown period, there was restriction in interstate movement and self-inhibition of the people's travel during the COVID pandemic, leading to fewer cases of RTA. Self-fall (16.9\% vs. $38.1 \%)$ and assault (11.2\% vs. $19 \%$ ) both increased in frequency during the lockdown period in our study. The increase in self-fall may be due to the shift of mode of injury from RTA to other causes, while factors such as alcohol withdrawal, syncopal attacks, or fall due to other unchecked 
medical comorbidities may have increased due to fewer visits to hospitals for their chronic medical illnesses. Interpersonal violence and assault have also increased in this COVID period due to the stress of acquiring the COVID disease, economic instability, and least social support. ${ }^{7}$

In both groups, most of the traumas were observed in males, with increased male gender predominance in TBI. According to the Ministry of Road Transport, male predominance in RTA, 130,144 (86.0\%), was found, similar to our study. The chance of injuries in males is more than females because of males' increased outdoor activities, as seen in TBI in the general population. ${ }^{11}$

The most common type of TBI was a mild head injury in both the groups (69.4\% vs. $61.9 \%$ ), while moderate TBI has increased during the lockdown period (19.4\% vs. 33.3\%), and severe head injury has slightly decreased during the lockdown period (11.2\% vs. $4.7 \%$ ) (-Fig. 3). The possibility of increased moderate TBI during the lockdown period has been explained by delayed referral and treatment of mild TBI patients and fewer visits to the hospital because of the fear of having a virus infection. ${ }^{7}$ The slight decrease of severe TBI in the lockdown period was because of the restriction of public transportations.

We have seen that contusion was the most frequent radiological diagnosis in both cohorts (54.03\% vs. $45.3 \%$ ), followed by aSDH (22.6\% vs. $21.4 \%)$, depressed fracture (12.1\% vs. $14.3 \%), \operatorname{EDH}(6.4 \%$ vs. $12 \%)$, and DAI (4.8\% vs. $7 \%$ ) (-Fig. 4 ).

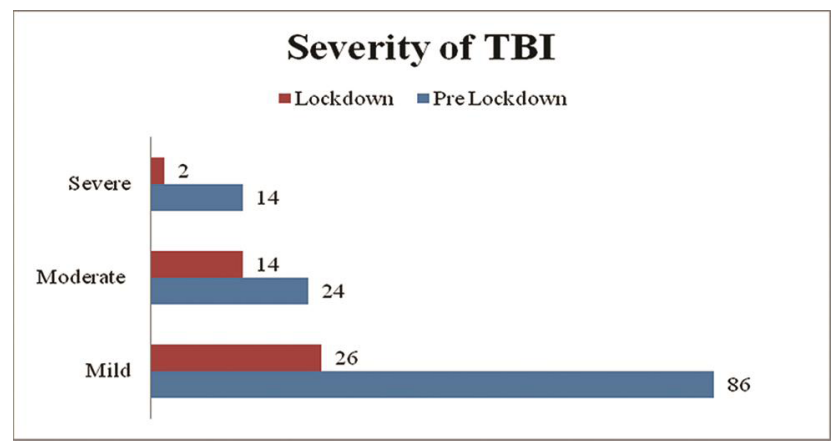

Fig. 3 Bar diagram shows difference of distribution of severity of traumatic brain injury (TBI) in the prelockdown and lockdown period.

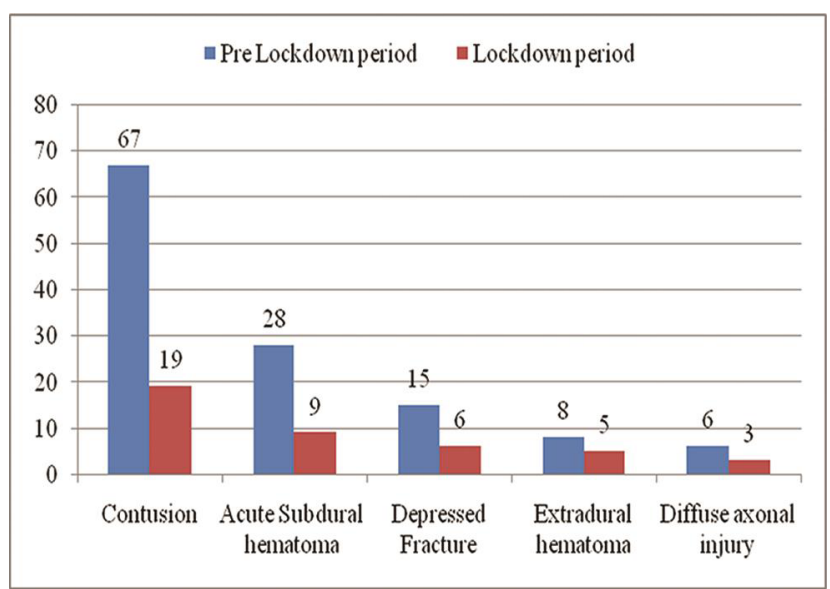

Fig. 4 Bar diagram shows various types of radiological diagnosis of admitted traumatic brain injury (TBI) cases.
A similar distribution of radiological diagnosis in TBI was also reported in other studies in India. ${ }^{12}$

Medical management was the most common treatment modality in both groups ( $85.5 \%$ vs. $90.5 \%$ ). Frequencies of surgical management in both groups are almost similar (14.5\% vs. 9.5\%). A total of 5 patients (4.03\%) have expired during the prelockdown period, and the death of only 2 patients $(4.8 \%)$ was reported in the lockdown period. In the prelockdown period, all 5 expired patients had severe TBI ( 2 with a frontotemporal contusion, 1 with aSDH, and 2 with DAI). Two died in the lockdown period-one with moderate TBI, diagnosed as a frontal contusion, and managed medically but developed respiratory difficulty on the second day of admission and found to be COVID positive. On the fourth day of admission, he expired with respiratory failure. Simultaneously, another patient presented as severe TBI, diagnosed as EDH with sinus injury, and underwent surgical intervention but died on the second postoperative day.

When we have analyzed the TBI patients' frequencies in both the prelockdown and lockdown period, there was a $67 \%$ reduction of TBI patients in the lockdown period. A similar reduction of TBI during the lockdown period has been noticed in other studies of India and other COVID-impacted countries. ${ }^{13,14}$ One study from New Zealand has shown a reduction of $43 \%$ of all-injury-related admissions, while one from Florida, United States, has also shown a $62 \%$ reduction in neurotrauma cases ${ }^{6,15}$ and one online survey from India has reported a $76 \%$ reduction of emergency neurosurgical operative cases during the pandemic. ${ }^{5}$ Neurotrauma cases have decreased during the pandemic; the health system is collaterally damaged due to a shortage of health care workers at each level and limited health infrastructure for fighting the pandemic. The government is taking measures for social and economic reforms.

\section{Limitations}

This study is a single institution study that is one of the major limitations of the study and the small size of the cohort. We have only included TBI patients exclusively and not included patients with spinal trauma. Because of these limitations, we cannot generalize our results to the whole population.

\section{Conclusion}

The COVID pandemic has affected every aspect of life and challenged our resources of the health care system. The limited road traffic activity and strict lockdown implementation have restricted the infection and have reduced neurotrauma emergencies. RTA is the main culprit for TBI in this phase, but a surprising increase in interpersonal violence and less frequent visits to the hospital for chronic illness has resulted in an increased self-fall and assault case.

\section{Funding \\ None.}

\section{Conflict of Interest}

None declared. 


\section{References}

1 Massenburg BB, Veetil DK, Raykar NP, Agrawal A, Roy N, Gerdin M. A systematic review of quantitative research on traumatic brain injury in India. Neurol India 2017;65(2):30531410.4103/neuroindia.NI_719_16

2 Hsiao M, Malhotra A, Thakur JS, et al; Million Death Study Collaborators. Road traffic injury mortality and its mechanisms in India: nationally representative mortality survey of 1.1 million homes. BMJ Open 2013;3(8):e002621

3 Ghosh P, Ghosh R, Chakraborty B. COVID-19 in India: Statewise Analysis and Prediction. JMIR Public Health Surveill. 2020;6(3):e20341

4 Bmj IC. Covid-19: India should abandon lockdown and refocus its testing policy, say public health specialists. BMJ 2020; 370:m3422

5 Venkataram T, Goyal N, Dash C, et al. Impact of the COVID-19 pandemic on neurosurgical practice in India: results of an anonymized national survey. Neurol India 2020;68(3): 595-602

6 Figueroa JM, Boddu J, Kader M, et al. The effects of lockdown during the severe acute respiratory syndrome coronavirus 2 (SARS-CoV-2) pandemic on neurotrauma-related hospital admissions. World Neurosurg Published online August 2020;187887502031850710.1016/j.wneu.2020.08.083

7 Lara-Reyna J, Yaeger KA, Rossitto CP, et al. "Staying Home"early changes in patterns of neurotrauma in New York City during the COVID-19 pandemic. World Neurosurg 2020;143: e344-e350
8 Dandona R, Kumar GA, Gururaj G, et al; India State-Level Disease Burden Initiative Road Injury Collaborators. Mortality due to road injuries in the states of India: the Global Burden of Disease Study 1990-2017. Lancet Public Health 2020;5(2):e86-e98

9 World Health Organization. (2018). Global status report on road safety 2018: Summary. In Global status report on road safety 2018: Summary

10 Ministry of Road Transport \& Highways Government of India, New Delhi, Transport Research Wing. Road Accidents in India 2018. Accessed February 6, 2021 at: https://morth.nic.in/sites/ default/files/Road_Accidednts.pdf.

11 Gururaj, G., S. V. R. Kolliri, and B. A. Chandramouli. Traumatic brain injury. National Inst Mental Health Neurosci 2005:61

12 Shekhar C, Gupta LN, Premsagar IC, Sinha M, Kishore J. An epidemiological study of traumatic brain injury cases in a trauma centre of New Delhi (India). J Emerg Trauma Shock 2015; 8(3):131-139

13 Fontanella MM, De Maria L, Zanin L, et al. Neurosurgical practice during the severe acute respiratory syndrome coronavirus 2 (SARS-CoV-2) pandemic: a worldwide survey. World Neurosurg 2020;139:e818-e826

14 Pinggera D, Klein B, Thomé C, Grassner L. The influence of the COVID-19 pandemic on traumatic brain injuries in Tyrol: experiences from a state under lockdown. Eur J Trauma Emerg Surg 2021;47(3):653-658

15 Christey G, Amey J, Campbell A, Smith A. Variation in volumes and characteristics of trauma patients admitted to a level one trauma centre during national level 4 lockdown for COVID-19 in New Zealand. N Z Med J 2020;133(1513):81-88 